Alma Mater Studiorum - Università di Bologna DEPARTMENT OF ECONOMICS

\title{
Optimal liability design under risk and ambiguity
}

Luigi Alberto Franzoni

Quaderni - Working Paper DSE $N^{\circ} 1048$

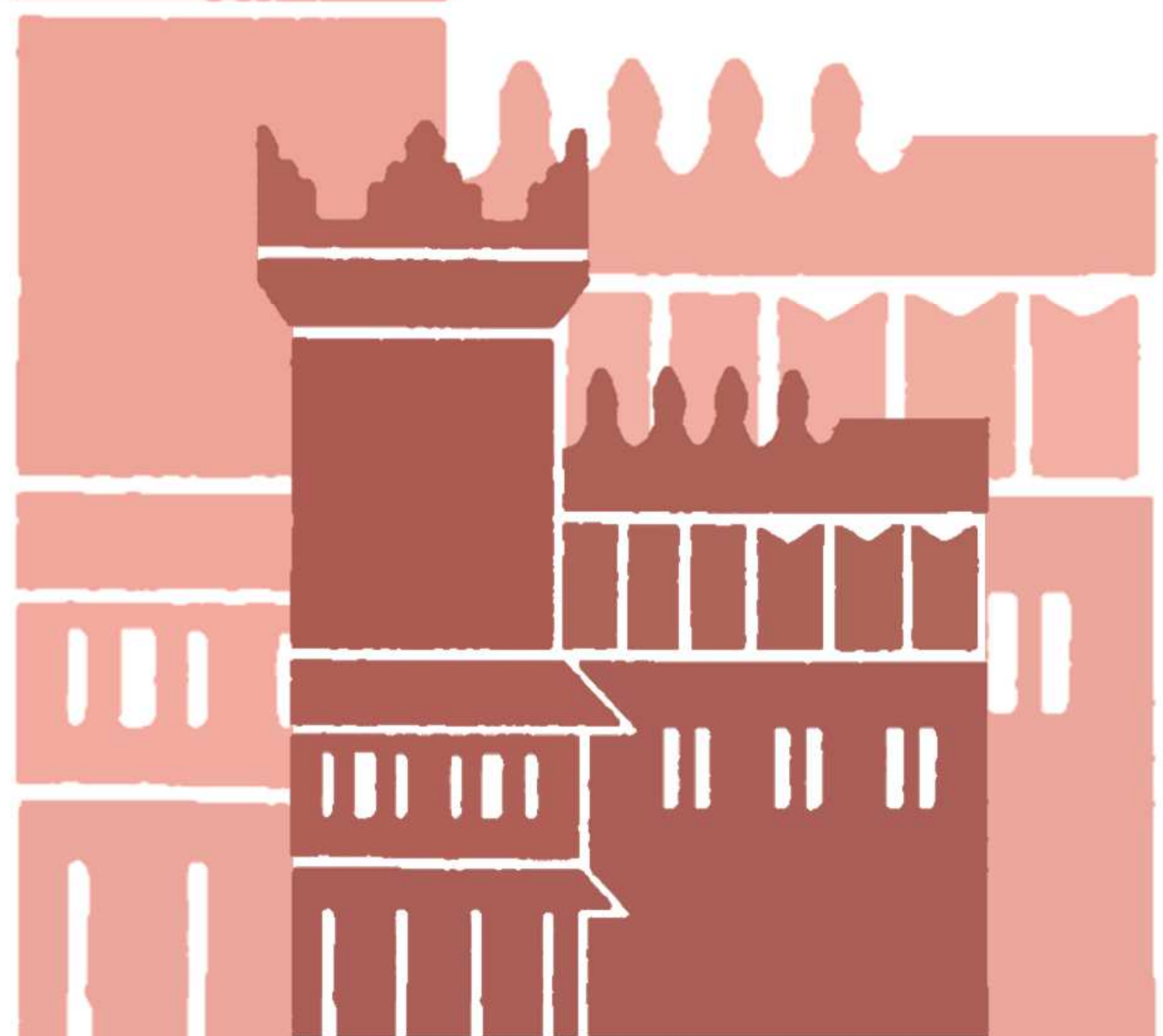




\title{
Optimal liability design under risk and ambiguity
}

\author{
Luigi Alberto Franzoni*†
}

November 2015

\begin{abstract}
This paper develops an original mean-variance model able to capture the disposition of the parties towards both standard risk and ambiguity. Ambiguity arises when the causal link between conduct and harm is not univocal, as is frequently the case with toxic torts. Risk aversion and ambiguity aversion tend to have a similar impact on optimal liability rules if greater care reduces the ambiguity perceived by the parties, i.e. if safety and predictability go hand in hand. Strict liability dominates negligence when the injurer has lower degrees of risk and ambiguity aversion than the victim and can formulate less ambiguous estimates of the probability of harm. The reverse result only holds under stronger conditions.
\end{abstract}

Keywords: negligence vs. strict liability, scientific uncertainty, ambiguity, toxic torts.

JEL Code: K13

${ }^{*}$ Correspondence to: Luigi A. Franzoni, Department of Economics, Piazza Scaravilli 2, 40126 Bologna, Italy.

${ }^{\dagger}$ This paper is the first part of a larger project originally titled "Liability law and uncertainty spreading." I am grateful to Fabio Maccheroni and Massimo Marinacci for valuable help. Thanks also to S. Bose, A. Daughety, M. Faure, G. Dari Mattiacci, D. Heine, E. Langlais, J. Reinganum, F. Parisi, S. Romagnoli, S. Shavell, O. Somech, L. Visscher, A. Tabbach, U. Schweizer, and seminar participants in Bologna, Bonn, Ghent, Stockholm (EALE), Standford (ALEA), and Tel Aviv for constructive comments. 
Liability rules allocate risks across individuals. As such, they serve both an incentive function (encouraging parties to take care) and an allocative function (uncertainty sharing). Optimal liability law design accordingly involves a difficult trade-off, in which the ability of the parties to take measures to avoid harm is balanced against their tolerance for uncertainty.

In this paper, I focus on uncertainty that arises when parties: i) do not know for sure whether harm will occur or not ("risk"), and ii) do not know for sure the probability with which harm will occur ("ambiguity"). The latter type of uncertainty is of special relevance for toxic torts, in which the connection between the injurer's conduct and the plaintiff's injury (the probability of harm) is often subject to scientific uncertainty due to our scant knowledge of the biological mechanisms for disease development. ${ }^{1}$ The ever expanding scope of the uncertainty brought about by technological progress poses a serious challenge to liability law and safety policy in general.

In the model, when agents assess preventive measures available (choice of care), they consider the ability of these measures to reduce the mean probability of harm as well the accuracy by which this reduction can be achieved. Specifically, I assume that parties formulate beliefs about the probability of harm given the preventive measures adopted. If these beliefs are dispersed (say, the probability of harm can range within an interval), the preventive measure generates ambiguity. In line with Ellsberg (1961) and an impressive body of empirical evidence, I assume that people are averse both to risk and ambiguity. ${ }^{2}$ Ambiguity aversion is modelled according to the smooth model of Klibanoff et al. (2005), which posits that parties are averse to mean preserving spreads of the beliefs.

\footnotetext{
${ }^{1}$ Scientific uncertainty has been a distinguishing trait of leading toxic torts, including asbestos, Agent Orange, Dalkon Shield, DES, and Bendectin (see, for instance, Geistfeld (2001), and references therein). In risk assessment, a distinction is normally drawn between "model" and "parameter" uncertainty. The first concerns the explanatory model, the latter only some parameters of the model (see for instance InstituteofMedicine (2014)). This paper deals with both types of uncertainty.

${ }^{2}$ The literature, both theoretical and empirical, on ambiguity aversion is huge. Good surveys are provided by Wakker (2010), Etner et al. (2012) and Gilboa and Marinacci (2013). In the medical field it has been shown that ambiguity regarding the effectiveness of health-protective measures, including cancer screening tests, makes people less willing to adopt them (see Reyna et al. (2015) and references therein).
} 
In order to overcome the complexities of the analysis - risk aversion alone is enough to cloud any intuition - I rely on local approximations of the willingness of the parties to bear uncertainty. ${ }^{3}$ This allows me to obtain an original mean-variance model in which the premium that an individual is willing to pay to avoid uncertainty is the sum of a risk premium and an ambiguity premium. The risk premium depends on the variance of the mean probability of harm, while the ambiguity premium depends on the variance of the beliefs, as in Maccheroni et al. (2013). On the basis of this convenient simplification, I am able to characterize the optimal features of the Negligence and Strict Liability rules, and to clearly identify the conditions under which either rule is socially preferable.

Section 2 deals with the optimal design of Strict Liability and Negligence. Neither rule produces the fully efficient outcome. Under Strict Liability, the double goal of setting incentives and allocating the uncertainty burden are assigned to a single instrument, namely damages. I show that optimal damages are less than fully compensatory. They increase with the degree of risk aversion of the victim, while their increases with his degree of ambiguity aversion if greater care reduces the variance of his beliefs.

Under Negligence, the injurer pays damages only if she does not meet the standard of care set by the courts. In equilibrium, the injurer will meet the standard and thus avoid liability. This implies that the uncertainty burden will be inefficiently placed on one side only (the victim). I show that the optimal standard of care is higher if the degree of risk aversion of the victim is higher. The optimal standard rises with the degree of ambiguity aversion of the victim if, and only if, care reduces the variance of his beliefs. In other words, adoption of those prevention measures should be discouraged at the margin, that reduce the mean probability of harm but increase the ambiguity borne by the victim (the ability of these measures to reduce the probability of harm is uncertain). In this sense, the cautionary approach underpinned by ambiguity aversion does not necessarily push for the use of "safer" (in expected terms) technologies: the predictability/reliability of these technologies matters too.

In Section 2.3, I address the main issue in liability design, namely which party

\footnotetext{
${ }^{3}$ These approximations allow for an analysis of liability policy independent of income levels, a convention that comports with current practice and standard cost-benefit analysis.
} 
should bear the loss. Strict Liability dominates Negligence when the injurer is less averse to uncertainty (either because of lower degrees of risk and ambiguity aversion or because she is able to formulate more precise estimates of the probability of harm). The reverse does not hold true: if courts can award under-compensatory damages, Strict Liability may dominate Negligence even if the victim is less averse to uncertainty than the injurer. Negligence definitely dominates if the degrees of risk and ambiguity aversion of the victim are sufficiently small or if the harm is dispersed on a large number of individuals. In the latter case, Negligence allows for better uncertainty spreading. These results hold for both unilateral and bilateral accidents where the defence under Strict Liability is contributory Negligence (Section 3).

Literature review. The relative performance of Strict Liability vis-a-vis Negligence has long been debated. Under uncertainty-neutrality, both rules can provide parties with an incentive to adopt the efficient level of care. The comparison between Strict Liability and Negligence must then account for additional factors, such as activity levels, judicial errors, judgment-proofness, and litigation expenditure. ${ }^{4}$ If the assumption of uncertainty neutrality is dropped, the disposition of the parties towards uncertainty becomes paramount and the two liability rules are no longer equivalent.

In his classic analysis of liability design under risk aversion, Shavell (1982) shows that Strict liability is preferable when the injurer is risk-neutral and the victim riskaverse, while Negligence is preferable in the opposite case. ${ }^{5}$ Beyond these polar cases, no further conclusion can be reached because attitudes towards risk themselves depend on the liability rule adopted. Another important result, found in Shavell (1982), is that optimal damages under Strict Liability are under-compensatory. ${ }^{6}$ This result holds in my (smooth) uncertainty model, but it does not hold when the beliefs of the parties

\footnotetext{
${ }^{4}$ See Shavell (2007), Schaefer and Mueller-Langer (2009), and references therein.

${ }^{5}$ Other investigations of optimal liability design under risk aversion include Greenwood and Ingene (1978), deriving optimal risk sharing rules using a local approach, and Graff Zivin and Small (2003), dealing with bilateral accidents with side payments under CRRA utilities. Nell and Richter (2003) address the case of dispersed harm under CARA utilities. They prove that negligence is approximately efficient when the number of victims goes to infinity, if care is constrained above. Langlais (2010) investigates optimal risk allocation for perfectly correlated harms under RDEU.

${ }^{6}$ This result derives from the basic insight of Mossin (1968) that a minimal amount of self-insurance is optimal when insurance premia include a loading factor (i.e., when they are not actuarially fair).
} 
are biased (see Appendix A6).

A closely related work is the pioneering contribution of Teitelbaum (2007), who uses Choquet's Expected Utility theory to account for the injurer's aversion to ambiguity in a unilateral accident model. Teitelbaum posits that when parties lack confidence on the probability of harm they make decisions taking an average of the best outcome (no accident), the worst outcome (accident) and the expected utility of the accident prospect. If they display "pessimism" they attach greater weight to the worst outcome, if they display "optimism," they attach greater weight to the best outcome. ${ }^{7}$ Teitelbaum assumes that the court and the victim are immune to ambiguity and investigates the impact of the injurer's ambiguity aversion on her choice of care, which tends to be biased. He shows that Negligence tends to outperform Strict Liability, since under the latter the injurer has to make a finer decision (what level of care to take, rather than whether to meet the standard or not). In this sense, Negligence allows for better "insulation" of non-rational behavior. ${ }^{8}$

In my model, the uncertainty about the probability of harm is ingrained in the prevention technology: it cannot be resolved. As such, it affects both the injurer and the victim. Furthermore, ambiguity aversion is taken as a rational response to probabilistic uncertainty, rather than a cognitive bias. As originally noted by Ellsberg (1961), ambiguity aversion is not a mistake that agents would be willing to correct once noted. Instead, ambiguity aversion is the manifestation of a rational doubt about the reliability of subjective beliefs (the probability estimates). ${ }^{9}$ If one takes this approach and includes ambiguity costs in welfare evaluations, then the relevant question becomes not how to force people to behave as if they were ambiguity-neutral, but rather how to allocate the loss when people have to bear the cost of uncertainty.

In the last decades, the study of ambiguity has been a hot topic in decision theory. Among the several models that have been proposed, the smooth model has proved particularly fruitful, since it provides an intuitive interpretation of ambiguity that can

\footnotetext{
${ }^{7}$ Optimism and pessimism can also be embedded in my smooth model, see Appendix A6.

${ }^{8}$ See Jolls and Sunstein (2006) for a broad view on insulation and debiasing approaches in behavioural law and economics.

${ }^{9}$ See the convincing arguments of Gilboa and Marinacci (2013), and references therein.
} 
encompass most other approaches (see Etner et al. (2012)). Treich (2010) shows that smooth ambiguity aversion increases the willingness to pay to reduce mortality risks. Snow (2011) and Alary et al. (2013) analyze the investment in self-protection and selfinsurance of ambiguity-averse agents. The effect of ambiguity on self-protection turns out to depend on the relationship between effort and beliefs. If the effort to self-protect is relatively less efficacious for more pessimistic beliefs, ambiguity reduces the marginal benefit of effort, and effort decreases (Alary et al. (2013)). ${ }^{10}$ Snow (2011) assumes that effort has a multiplicative effect on beliefs, which implies that it is more effective for pessimistic beliefs (high probabilities of harm). As a result, in his model ambiguity increases the self-protection effort. My model is consistent with both insights. ${ }^{11}$

\section{Uncertainty aversion}

Let us consider the case in which an injurer (I) can cause harm $h$ to a victim (V). Assume first that the probability of harm is $\pi(x)$, where $x$ is the level of care taken by the injurer and $\pi(x)$ is common knowledge. Liability law determines whether the victim is entitled to recover damages from the injurer. Let us assume, for the time being, that damages $d$ are awarded. The victims bears loss $h-d$ in case of accident.

The expected utility of the victim, given the probability of harm $\pi(x)$, is

$$
E U_{\pi(x)}=(1-\pi(x)) u\left(i_{V}\right)+\pi(x) u\left(i_{V}-(h-d)\right),
$$

where $i_{V}$ is his income.

If we take a second order approximation of the utility function, we obtain an expression for the payoff of victim that depends only on the mean and the variance of the loss prospect. The certainty equivalent $c_{\pi(x)}$ of the accident prospect (such that

\footnotetext{
${ }^{10} \mathrm{~A}$ related result, applied to optimal pollution abatement, is obtained by Millner et al. (2013).

${ }^{11}$ Berger et al. (2013) show that a patient's propensity to opt for treatment increases with (smooth) ambiguity if ambiguity regards the diagnosis, while it decreases with ambiguity if ambiguity regards the effects of treatment. This pattern is explained by the fact that ambiguity averse individuals tend to overweight the bad states of the world.
} 
$\left.u\left(c_{\pi(x)}\right)=E U_{\pi(x)}\right)$ can be written as:

$$
c_{\pi(x)}=i_{V}-\pi(x)(h-d)-\frac{1}{2} \rho_{V} \sigma_{\pi(x)}^{2}(h-d)^{2},
$$

where $\pi(x)(h-d)$ is the expected loss, $\sigma_{\pi(x)}^{2}=\pi(x)(1-\pi(x))$ the variance of the unit loss, and $\rho_{V}$ the Arrow-Pratt degree of absolute risk aversion of the victim (see Pratt (1964)).

Suppose now that the probability of harm is uncertain: the victim formulates beliefs about $\pi(x)$. Let $\mu_{V}$ be the probability distribution over beliefs $\pi(x)$. The more dispersed the beliefs, and the higher the ambiguity.

Figure 1 illustrates the case in which two (equally plausible) models of individual dose-response to an environmental chemical are available. Under model A the "safety threshold" is $x^{A}$, while under model $\mathrm{B}$ it is $x^{B}$ (here care reduces the exposition to the chemical). ${ }^{12}$

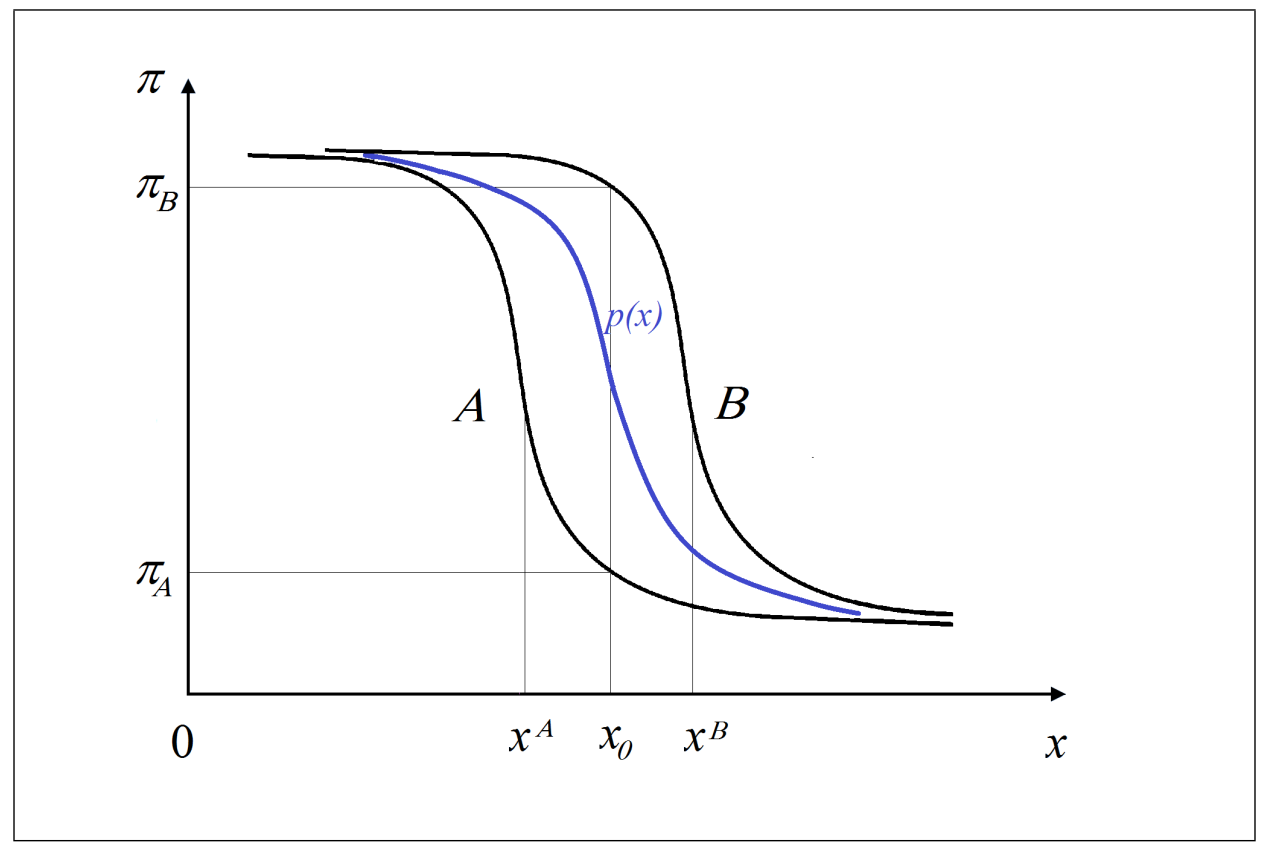

Fig. 1. Dose response uncertainty.

\footnotetext{
${ }^{12}$ See the recent report of the NRC (National-Research-Council (2009)) for the extensive implications of scientific uncertainty, including dose response, on risk assessment.
} 
For intermediate levels of care, ambiguity is high. ${ }^{13}$ Given the level of care $x_{0}$, for instance, the probability of harm is $\pi_{A}$ under the first model and $\pi_{B}$ under the second model. Under Expected Utility theory, the distribution of the beliefs is irrelevant: the only thing that matters is the mean probability of harm: $p(x)=E_{\mu}(\pi(x))$. This corresponds to the case of an ambiguity-neutral agent. Ambiguity-averse agents, instead, tend to dislike choice environments where probabilities are not known for sure (they are averse to mean preserving spreads of the beliefs). Instead of maximizing the simple mean of the Expected Utilities associated to the different beliefs, they maximize the mean of a concave transformation $\varphi$ of the expected utilities. Fig. 2 illustrates.

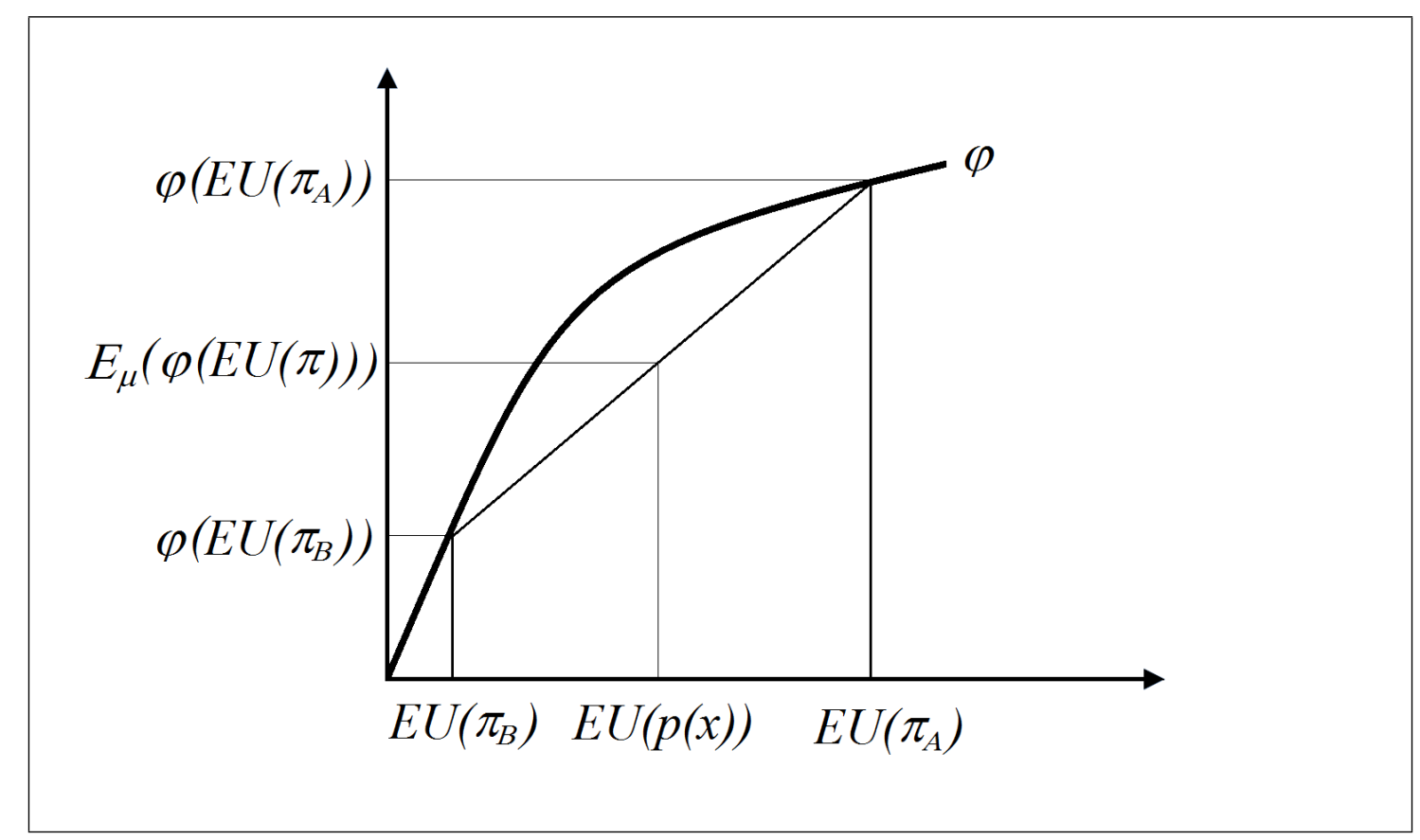

Fig. 2. Ambiguity aversion.

Given $x_{0}$, under model A, the agent gets Expected Utility $E U\left(\pi_{A}\right)$, while under model B he gets $E U\left(\pi_{B}\right)$. Aversion to ambiguity is captured by the curvature of the $\varphi$ function: the welfare the agent obtains from this ambiguous situation, $E_{\mu}(\varphi(E U(\pi)))$,

\footnotetext{
${ }^{13}$ In this example, the relationship between care and ambiguity (dispersion of beliefs) is nonmonotonic. In what follows, I make no specific assumptions of the shape of this relationship, although some results only apply if ambiguity decreases with care.
} 
is less than the welfare he would get if the probability of harm were $p(x)$ for sure, $\varphi(E U(p(x)))$. Note how the smooth model (differently from most non-EU models) allows for a clear distinction between risk aversion (the curvature of the utility function), ambiguity (the dispersion of the beliefs), and ambiguity aversion (the curvature of the transformation function). ${ }^{14}$

By applying a second order approximation to the transformation function $\varphi$, I obtain an original mean-variance model (see Appendix A1), in which the certainty equivalent for the victim can be written as

$$
C_{V}(x)=i_{V}-p(x)(h-d)-\frac{1}{2} \Psi_{V}(x)(h-d)^{2} .
$$

The uncertainty premium has a simple shape:

$$
\underbrace{\frac{1}{2} \Psi_{V}(x)(h-d)^{2}}_{\text {uncertainty premium }}=\underbrace{\frac{1}{2} \rho_{V} \sigma_{p(x)}^{2}(h-d)^{2}}_{\text {risk premium }}+\underbrace{\frac{1}{2} \theta_{V} \sigma_{\mu_{V}}^{2}(\pi(x))(h-d)^{2}}_{\text {ambiguity premium }} .
$$

The uncertainty premium is equal to the sum of the risk and ambiguity premia. The risk premium is one half of the degree of risk aversion $\rho_{V}$ times the variance generated by the mean probability of harm times the square of the loss. The ambiguity premium is one half of the agent's degree of ambiguity aversion $\theta_{V}$ times the variance of the prior beliefs times the square of the loss. The uncertainty index:

$$
\Psi_{V}(x)=\rho_{V} \sigma_{p(x)}^{2}+\theta_{V} \sigma_{\mu_{V}}^{2}(\pi(x))
$$

is thus a local measure of the costs of risk and ambiguity for the victim. It depends on two taste parameters $\left(\rho_{V}\right.$ and $\left.\theta_{V}\right)$ and two uncertainty measures $\left(\sigma_{p(x)}^{2}\right.$ and $\sigma_{\mu_{V}}^{2}(\pi(x))$. Note that the uncertainty premium smoothly converges to zero as the loss goes to zero (henceforth the name "smooth model").

In the following, I will assume that the victim (as the injurer) is neither risk nor

\footnotetext{
${ }^{14}$ If the agent is infinitely averse to ambiguity, he behaves as if the probability of harm were the largest among the possible ones (in his beliefs set), in line with the Maximin Expected Utility of Gilboa and Schmeidler (1989).
} 
ambiguity lover: $\rho_{V} \geq 0, \theta_{V} \geq 0 .{ }^{15}$ Results can be easily adapted to the opposite case.

Before turning to the injurer, I need to make some assumptions on the structure of the beliefs. The injurer and the victim can have different priors about the probability of harms $\pi(x)$. I assume, however, that these priors share (at least) the same mean $p(x)$ : parties formulate unbiased estimates of the probability of harm. In this sense, harm is "foreseeable." 16 A more radical departure from the traditional theory is represented by the case in which parties do not agree on the mean probability of harm and have, therefore, diverging expectations. The latter case is analyzed in Appendix A6.

Assumption 1 Foreseeability. For all levels of care $x \geq 0$, the beliefs of the injurer and the victim are correct on average: $E_{\mu_{I}}(\pi(x))=E_{\mu_{V}}(\pi(x)) \equiv p(x)$.

The beliefs of the parties can be characterized by different levels of ambiguity. As the ambiguity drops to zero, the model converges to the standard EU model, in which $p(x)$ is regarded as the "true" harm probability. ${ }^{17}$

Care is assumed to reduce the mean probability of harm at a decreasing rate. To better disentangle the effect of risk aversion, I further assume that the mean probability of harm is not too large.

Assumption 2 For any level of care: $p(x) \leq 1 / 2, p^{\prime}(x)<0$, and $p^{\prime \prime}(x)>0$.

The variance of the unit loss generated by the mean probability of harm is $\sigma_{p(x)}^{2}=$ $p(x)(1-p(x))$. This variance decreases with $x$ if Assumption 2 is met. ${ }^{18}$

\footnotetext{
${ }^{15}$ From auto collision insurance choices of households, the following baseline estimates of the absolute risk aversion index have been optained: $\rho \in[0.002,0.008]$ (Barseghyan et al. (2013)), $\rho \simeq 0.0067$ (Cohen and Einav (2007)), and $\rho \in[0.002,0.0053]$ (Sydnor (2010)). Conte and Hey (2013) and Attanasi et al. (2014) provide experimental estimates of the smooth model.

${ }^{16}$ Foreseeability of risks is a common requisite for liability to apply (at least after Feldman v. Lederle Laboratories, 479 A.2d 374, N.J. 1984). See Restatement (Third) of Torts: Liability for Physical Harm $\S 3,2005$. This paper does not address scientifically unknowable risks. Additionally, because the information set does not chance with time, it does not consider hindsight liability. On the latter, see Ben-Shahar (1998),

${ }^{17}$ To rationalize: when the evidence on harm is scarce or is conflicting, beliefs will be characterized by ambiguity. Here, $p(x)$ is just the mean belief. As the evidence accumulates, ambiguity disappears and $p(x)$ emerges as the "objective" probability of harm, known to all parties.

${ }^{18}$ Assumption 2 is stronger than necessary. What I really need is that the mean probability of harm is not greater than $1 / 2$ in equilibrium. Conducts yielding an equilibrium probability of harm greater than $1 / 2$ would probably qualify as reckless and wanton. They lie outside the scope of this paper.
} 
Let us now consider the injurer, on the assumption that she pays damages $d$ when an accident occurs. Her certainty equivalent can be written as:

$$
C_{I}(x)=i_{I}-x-p(x) d-\frac{1}{2} \Psi_{I}(x) d^{2},
$$

where $i_{I}$ is her income, $x$ the expenditure in care, and $\Psi_{I}(x)$ her uncertainty index:

$$
\Psi_{I}(x)=\rho_{I} \sigma_{p(x)}^{2}+\theta_{I} \sigma_{\mu_{I}}^{2}\left(\pi_{j}(x)\right) .
$$

Again, the uncertainty index includes a risk aversion component (index of risk aversion $\rho_{I}$ times the variance of the mean probability of harm) and an ambiguity aversion component (index of ambiguity aversion $\theta_{I}$ times the variance of her beliefs).

As the injurer invests more in care $x$, the expected liability payment $p(x) d$ decreases,

the risk premium $\frac{1}{2} \rho_{I} \sigma_{p(x)}^{2} d^{2}$ decreases, while the ambiguity premium can increase or decrease, depending on whether care increases or decreases the uncertainty regarding the probability of harm.

\section{Optimal liability design}

\subsection{Strict liability}

Under Strict Liability, the injurer pays compensation to the victim irrespective of the amount $x$ invested in precaution. Courts can affect the injurer's behavior and the allocation of uncertainty by means of the damages awarded $d$. Damages can fully compensate the victim $(d=h)$, they can overcompensate him, e.g., by including a punitive component, or they can under-compensate him, e.g., when caps are imposed or when some types of harm are deliberately excluded (e.g., pain and suffering).

The optimal level of $d$ is obtained from the maximization of Social Welfare

$$
\begin{aligned}
S W^{S L} & =C_{I}\left(x_{0}\right)+C_{V}\left(x_{0}\right) \\
& =i_{I}-x_{0}-p\left(x_{0}\right) d-\frac{1}{2} \Psi_{I}\left(x_{0}\right) d^{2}+i_{V}-p\left(x_{0}\right)(h-d)-\frac{1}{2} \Psi_{I}\left(x_{0}\right) d^{2},
\end{aligned}
$$


Since $i_{I}, i_{V}$, and $h$ are constants, the problem is equivalent to the minimization of Social Loss:

$$
\min L^{S L}(d)=x_{0}+p\left(x_{0}\right) h+\frac{1}{2} \Psi_{I}\left(x_{0}\right) d^{2}+\frac{1}{2} \Psi_{V}\left(x_{0}\right)(h-d)^{2} .
$$

The care level $x_{0}$ is chosen by the injurer so as to maximize her certainty equivalent $C_{I}(x)$. She will set $x_{0}$ so that

$$
1=-p^{\prime}\left(x_{0}\right) d-\frac{1}{2} \Psi_{I}^{\prime}\left(x_{0}\right) d^{2}:
$$

an additional dollar spent in precaution reduces her expected liability and her uncertainty premium by one dollar.

We have:

$$
\Psi_{I}^{\prime}(x)=\rho_{I} \frac{d \sigma_{p(x)}^{2}}{d x}+\theta_{I} \frac{d \sigma_{\mu_{I}}^{2}\left(\pi_{j}(x)\right)}{d x}=\rho_{I} p^{\prime}(x)(1-2 p(x))+\theta_{I} \frac{\partial \sigma_{\mu_{I}}^{2}(\pi(x))}{\partial x}
$$

an increase in care reduces the variance of the mean probability of harm $p(x)$ (thanks to Assumption 2) and affects the level of ambiguity borne by the injurer. If care does not increase the variance of her prior, $\frac{\partial \sigma_{\mu_{I}}^{2}\left(\pi_{j}(x)\right)}{\partial x} \leq 0$, then: $\Psi_{I}^{\prime}(x)<0$.

From (9) and (8), we get that incentives to take care increase with the index of risk aversion $\rho_{I}$, while they increase with the index of ambiguity aversion $\theta_{I}$ if, and only if, $\frac{\partial \sigma_{\mu_{I}}^{2}\left(\pi_{j}(x)\right)}{\partial x}<0$.

Care increases with damages $d$ if, and only if, the following condition holds:

$$
p^{\prime}\left(x_{0}\right)+\Psi_{I}^{\prime}\left(x_{0}\right) d<0
$$

Condition (10) posits that care can increase ambiguity, but not too much. ${ }^{19}$ In what follows, I will assume that condition (10) is met for all levels of $d$. This condition is surely met when care does not increase ambiguity: $\frac{\partial \sigma_{\mu_{I}}^{2}(\pi(x))}{\partial x} \leq 0$.

\footnotetext{
${ }^{19}$ Eq. 10 can be written as $\theta_{I} \frac{\partial \sigma_{\mu_{I}}^{2}}{\partial x}<-p^{\prime}\left[\frac{1}{d}+(1-2 p) \rho_{I}\right]$. It is met if $-p^{\prime}$ is sufficiently large (care reduces substantially the mean probability of harm), $\theta_{I}$ is small, $\rho_{I}$ is large and $\frac{\partial \sigma_{\mu_{I}}^{2}}{\partial x}$ is small.
} 
By differentiation of (7), using (8), we get:

$$
\begin{aligned}
L^{S L^{\prime}}(d)= & \frac{\partial x_{0}}{\partial d}\left[p^{\prime}\left(x_{0}\right)(h-d)+\frac{1}{2} \Psi_{V}^{\prime}\left(x_{0}\right)(h-d)^{2}\right] \\
& +\Psi_{I}\left(x_{0}\right) d-\Psi_{V}\left(x_{0}\right)(h-d) .
\end{aligned}
$$

An increase in damages has two effects: i) it provides the injurer with additional incentives to take care and hence to reduce the "externality" she exerts on the victim (uncompensated harm and the attendant uncertainty premium), and ii) it shifts the uncertainty burden from the victim to the injurer.

By implicit differentiation of (11), we get: $\frac{\partial d^{*}}{\partial \rho_{V}}>0$. Furthermore, if $\frac{\partial \sigma_{\mu_{V}}^{2}\left(x_{0}\right)}{\partial x} \leq 0$, then $\frac{\partial d^{*}}{\partial \theta_{V}}>0$.

Note that for $d=h$, the "externality" effect vanishes and marginal social loss collapses to

$$
L^{S L \prime}(h)=\Psi_{I}\left(x_{0}\right) h \geq 0 .
$$

With fully compensatory damages $(d=h)$, incentives to take care would be appropriately set, since the injurer fully internalizes the consequences of her actions. However, the uncertainty would not be optimally allocated, since all of the burden would be placed on the injurer. If the injurer is not uncertainty neutral (i.e., if $\Psi_{I}\left(x_{0}\right)>0$ ), the allocation of uncertainty can be improved at the margin - with a negligible effect on the welfare of the victim - by reducing damages and shifting some of the uncertainty on the victim. The benefit for the injurer is of the first order, the cost for the victim of the second order.

Proposition 1 Strict liability. If the injurer is not uncertainty neutral, damages should be less than fully compensatory: $d^{*}<h$. Optimal damages increase with the index of risk aversion of the victim, $\rho_{V}$, while they increase with his index of ambiguity aversion, $\theta_{V}$, if care reduces the variance of his priors.

Under Strict Liability, courts control the level of the damages awarded. Using this tool, they should try and achieve two goals: i) provide incentives to take care, and ii) allocate the uncertainty burden. The first goal would be accomplished if damages were set equal to harm. This outcome, however, is not optimal in terms of uncertainty 
allocation, unless the injurer is uncertainty neutral. Thus, damages should leave a share of the loss on the victim. ${ }^{20}$

The impact of ambiguity on the optimal level of damages is not univocal. If the victim is subject to large ambiguity, a shift of the loss on the injurer might look desirable. However, if the injurer bears a larger share of the loss, she will take greater care. In turn, this might further increase the ambiguity borne by the victim (if the variance of his beliefs increases with $x$ ).

\subsection{Negligence}

Under a Negligence rule, the injurer pays compensatory damages $d=h$ only if she does not meet the due standard of care $\bar{x}$. Care is assumed to be verifiable in court. Unless the standard is prohibitively high, the injurer will prefer to meet it and avoid liability. I will thus assume that $x=\bar{x} \cdot{ }^{21}$ The optimal standard should be set so as to minimize

$$
L^{N}(\bar{x})=\bar{x}+p(\bar{x}) h+\frac{1}{2} \Psi_{V}(\bar{x}) h^{2} .
$$

All the uncertainty is borne by the victim.

The optimal standard $\bar{x}$ should solve:

$$
1=-p^{\prime}(\bar{x}) h-\frac{1}{2} \Psi_{V}^{\prime}(\bar{x}) h^{2}:
$$

an additional dollar spent on precaution should reduce expected harm and the uncertainty premia of the victim by one dollar.

We get $\frac{\partial \bar{x}}{\partial h}>0$ if, and only if: $p^{\prime}(\bar{x})+\Psi_{V}^{\prime}(\bar{x}) h<0$, which is assumed to hold. ${ }^{22}$

\footnotetext{
${ }^{20}$ In this model, the Injurer cannot escape responsibility. Thus, the standard rationale for punitive damages does not apply.

${ }^{21}$ The injurer prefers to be negligent if $\bar{x}>x^{*}+p\left(x^{*}\right) h+\frac{1}{2} \Psi_{I}\left(x^{*}\right) h^{2}$, where $x^{*}$ maximises injurer's welfare when she is liable. If that is the case, however, then $\bar{x}+p(\bar{x}) h+\Psi_{V}(\bar{x}) h^{2}>x^{*}+$ $p\left(x^{*}\right) h+\frac{1}{2} \Psi_{I}\left(x^{*}\right) h^{2}$, and the lawmaker itself would definitely prefer that the injurer did not meet the standard. The results of this paper also hold if damages (paid by the negligent injurer) differ from harm. However, damages cannot be too low, as otherwise the injurer prefers not to meet the standard and strict liability de facto applies.

${ }^{22}$ This assumption is the equivalent of Condition (10) applied to the Injurer.
} 
From (4) and Assumption 2, by implicit differentiation, we get: $\frac{\partial \bar{x}}{\partial \rho_{V}}>0$. Furthermore, $\frac{\partial \bar{x}}{\partial \theta_{V}}>0$ if, and only if: $\frac{\partial \sigma_{\mu_{V}}^{2}(\pi(\bar{x}))}{\partial x}<0$. Hence, the following.

Proposition 2 The optimal standard of care increases with the degree of risk aversion of the victim, $\rho_{V}$. It increases with his degree of ambiguity aversion, $\theta_{V}$, if, and only if, care reduces the variance of his prior.

The latter result identifies the condition under which ambiguity supports a cautionary approach to liability law: uncertainty about the probability of harm calls for a tighter safety standard if, and only if, care reduces the variance of the beliefs of the victim. While ambiguity surely increases the victim's uncertainty premium, one cannot say a priori whether ambiguity calls for greater prevention effort.

The optimal standard of care is obtained by balancing different (potentially conflicting) factors: costs of prevention effort $(x)$, effectiveness of this effort to reduce the mean probability of harm $\left(p^{\prime}(x)\right)$, ability of this effort to reduce the uncertainty borne by the potential victim (impact on $\sigma_{p(x)}^{2}$ and $\sigma_{\mu_{V}}^{2}(\pi(x))$. If $\frac{\partial \sigma_{\mu_{V}}^{2}(\pi(x))}{\partial x}>0$, the safest prevention measures turn out to be the less reliable ones: they reduce the mean probability of harm but increase the ambiguity borne by the victims. If victims are highly averse to ambiguity, the use of these measures should be discouraged.

\subsection{Strict liability vs. Negligence}

Both Negligence and Strict Liability provide second best solutions to the concomitant problems of optimal uncertainty allocation and harm prevention. Which rule is preferable? Under Negligence, the uncertainty is fully placed on the victim and the standard of care is (optimally) set by the courts. Under Strict Liability, uncertainty is shared at the optimum, and the level of care is chosen by the injurer.

To compare Strict Liability and Negligence, let us start from the special case in which damages are equal to harm: $d=h$. Here, constrained social loss amounts to:

$$
\widehat{L}^{S L}\left(x^{c}\right)=x^{c}+p\left(x^{c}\right) h+\frac{1}{2} \Psi_{I}\left(x^{c}\right) h^{2},
$$

where $x^{c}$ is the level of care chosen by the injurer (eq. 8). 
For any given level of care $x$, constrained Strict Liability (14) yields a lower ex-post social loss than Negligence (eq. 12) if, and only if:

$$
\widehat{L}^{S L}(x)<L^{N}(x) \Leftrightarrow \Psi_{I}(x)<\Psi_{V}(x)
$$

Given $x$, a rule placing the whole loss on the injurer is preferable to a rule placing it entirely on the victim if, and only if, the former is less averse to uncertainty than the latter. The following sharp conditions point to the best uncertainty bearers:

Condition I: for all $x, \Psi_{I}(x) \leq \Psi_{V}(x)$, Condition $V$ : for all $x, \Psi_{I}(x)>\Psi_{V}(x)$.

Under Condition I, for all levels of care, the injurer is the best uncertainty bearer. Under Condition $V$, the victim is the best uncertainty bearer.

Let us suppose that Condition $I$ holds: given the optimal level of care under Negligence $x^{n}$, Strict Liability with compensatory damages is preferable to Negligence: $\widehat{L}^{S L}\left(x^{n}\right) \leq L^{N}\left(x^{n}\right)$. Social loss is even lower, under constrained Strict Liability, if the injurer is free to chose the level of care $x^{c}$ that maximizes her welfare (the welfare level of the victims is not affected): $\widehat{L}^{S L}\left(x^{c}\right) \leq \widehat{L}^{S L}\left(x^{n}\right)$. Social loss further declines if damages are optimally set: $L^{S L}\left(x_{0}\right)<\widehat{L}^{S L}\left(x^{c}\right)$, where $x_{0}$ is the level of care taken by the injurer when $d=d^{*}<h$. Thus, if Condition I holds, Strict Liability dominates Negligence.

Let us suppose now that Condition $V$ holds. Given the level of care $x^{c}$ chosen by the injurer under Strict Liability with compensatory damages, Negligence entails a lower social loss: $L^{N}\left(x^{c}\right)<\widehat{L}^{S L}\left(x^{c}\right)$. Social loss further decreases, under Negligence, if the

level of care is optimally chosen by the courts: $L^{N}\left(x^{n}\right) \leq L^{N}\left(x^{c}\right)$. We have thus proved the following:

\section{Proposition 3 Strict liability vs. Negligence.}

i) if Condition I holds, Strict Liability dominates Negligence.

ii) If Condition $V$ holds, Negligence dominates Strict Liability when damages are fully compensatory $(d=h)$. 
Proposition 3 identifies some clear cut conditions for the choice between liability rules. These conditions are based on the ability of the parties to tolerate uncertainty. In turn, this ability depends on their degrees of aversion to risk and ambiguity, and on the dispersion of their beliefs. ${ }^{23}$ The result, however, is not symmetric: when courts can suitable chose the level of damages, Condition $\mathrm{V}$ is not enough to guarantee that Negligence is preferable. Dominance of Negligence can only be obtained under stronger conditions.

From (12) and (7), one can see that

$$
L^{N}\left(x^{s}\right)<L^{S}\left(x^{s}\right) \Leftrightarrow \Psi_{V}\left(x^{s}\right) h^{2}<\Psi_{I}\left(x^{s}\right) d^{* 2}+\Psi_{V}\left(x^{s}\right)\left(h-d^{*}\right)^{2},
$$

where $x^{s}$ is the care level chosen by the injurer under Strict Liability, which simplifies to

$$
L^{N}\left(x^{s}\right)<L^{S}\left(x^{s}\right) \Leftrightarrow \frac{d^{*}}{h}>2 \frac{\Psi_{V}\left(x^{s}\right)}{\Psi_{V}\left(x^{s}\right)+\Psi_{I}\left(x^{s}\right)} .
$$

Since $d^{*}<h$, inequality (16) can be met only if $\Psi_{V}\left(x^{s}\right)<\Psi_{I}\left(x^{s}\right)$.

Note that $\frac{\Psi_{V}\left(x^{s}\right)}{\Psi_{V}\left(x^{s}\right)+\Psi_{I}\left(x^{s}\right)}$ converges to zero if $\Psi_{V}\left(x^{s}\right)$ becomes small, while optimal damages $d^{*}$ do not (the injurer needs to be motivated, see Appendix A3). Thus, inequality (16) is met if $\rho_{V}$ and $\theta_{V}$ are both sufficiently small. If this is the case, then

$$
L^{N}\left(x^{n}\right) \leq L^{N}\left(x^{s}\right)<L^{S}\left(x^{s}\right),
$$

where $x^{n}$ is the optimal level of care chosen by the courts: Negligence dominates Strict Liability.

Proposition 4 When damages are optimally set by the courts, Negligence dominates Strict Liability if the degrees of risk and ambiguity aversion of the victim are sufficiently small.

Also for this Proposition, note that the condition used is sufficient but not necessary.

\footnotetext{
${ }^{23}$ If $\sigma_{\mu_{V}}^{2}(\pi(x))$ and $\sigma_{\mu_{I}}^{2}(\pi(x))$ are affected in different ways by $x$, one can have situations in which neither Condition I nor $\mathrm{V}$ hold (the victim might be the best uncertainty bearers for some levels of $x$, but not for others). Note, however, that dominance of strict liability only requires: $\Psi_{I}\left(x^{n}\right)<\Psi_{V}\left(x^{n}\right)$. Dominance of negligence only requires: $\Psi_{I}\left(x_{0}\right)>\Psi_{V}\left(x_{0}\right)$.
} 


\section{Bilateral accidents}

In this section, I touch upon the case in which the victim can affect his likelihood of suffering harm. For instance, by wearing protective clothes, an individual can reduce the risk of burn injuries.

I concentrate on two liability rules: simple Negligence and Strict Liability with the defence of contributory negligence. The latter defence is necessary to provide the victim with incentives to take care (see Shavell (2007)).

Both liability rules are able to provide incentives to take care (the analysis is provided in Appendix A4). Under Strict Liability with contributory negligence, the injurer selects care so as to minimize the difference between his liability burden and the cost of care; the victim takes care so as to avoid liability. Optimal damages are undercompensatory. Under Negligence, the injurer meets the standard of care; the victim selects care so as to minimize the difference between the burden of harm and the cost of care. The optimal standard of care for the injurer increases with the degree of risk aversion of the victim, while it increases with the degree of ambiguity aversion of the latter if care (of both sides) reduces the variance of the prior of the victim (on the assumption that cross-effects do not go in the opposite direction or that they are small enough).

In the comparison between liability rules, Propositions 3 and 4 apply. Thus, Strict liability with the defence of contributory negligence is preferable, if the victim is at least as averse to uncertainty as the injurer. Negligence is preferable if the victim's aversion to uncertainty is weak enough.

\section{Dispersed harm}

Let us consider the case in which victims are numerous. For simplicity, I posit that all $n$ victims are alike: they all suffer harm $h$, and they are all equally averse to risk and ambiguity: for all $j=\{1,2, \ldots, n\}$ and for all $x \geq 0, \Psi_{V j}(x)=\Psi_{V}(x)$. Let total harm be $n h=H$; total damages $n d=D$. 
Social loss under Strict Liability can now be written as (omitting arguments):

$$
\begin{aligned}
L^{S L} & =x_{0}+p n h+\frac{1}{2} \Psi_{I}(n d)^{2}+n \frac{1}{2} \Psi_{V}(h-d)^{2}= \\
& =x_{0}+p H+\frac{1}{2} \Psi_{I} D^{2}+\frac{1}{2} \frac{\Psi_{V}}{n}(H-D)^{2},
\end{aligned}
$$

where $x_{0}$ is chosen by the injurer (so we are back to the case in which only the injurer takes care, but this is immaterial).

Under Negligence we have instead

$$
L^{N}(\bar{x})=\bar{x}+p(\bar{x}) n h+n \frac{1}{2} \Psi_{V}(\bar{x}) h^{2}=\bar{x}+p(\bar{x}) H+\frac{1}{2} \frac{\Psi_{V}}{n}(\bar{x}) H^{2} .
$$

The loss functions are equivalent to the loss functions of the basic problem, but now the victim's degree of uncertainty aversion is divided by $n$. So, if if $n$ is sufficiently large, the (equivalent of) both Condition V and inequality (16) are met. Hence, Proposition 3 , part ii), as well as Proposition 4 apply.

Proposition 5 If the number of victims is sufficiently large, Negligence dominates Strict Liability.

The intuition for this result is straightforward. Since the Uncertainty Premium increases more than proportionally with the loss, the loss should not be entirely placed on the injurer. A liability rule spreading uncertainty tends to be preferable, as originally argued by Nell and Richter (2003) with respect to standard risk. ${ }^{24}$

\section{$5 \quad$ Final remarks}

This paper sheds light on the optimal structure of liability law in an uncertain world in which the activity of the injurer generates both risk and ambiguity. Since most people

\footnotetext{
${ }^{24}$ Nell and Richter (2003) prove that, if care is bounded above, then negligence is approximately first best efficient for $n \rightarrow \infty$ (see Appendix A5). Without restricting $x$, I identify the condition for the superiority of negligence both for unilateral and bilateral accidents under risk and ambiguity. Proposition 5 holds also for finite levels of total harm $H$.
} 
are risk and ambiguity averse, the inclusion of uncertainty substantially adds to the realism of the analysis. There are good reasons to believe that for toxic torts and newly developed technologies, the ambiguity component of uncertainty is likely to be by far the most important.

In a first best world, in which the policy maker could control both the amount of care taken by individuals and the share of the loss borne by each one (de facto, a system with regulation and social insurance), each agent would exert care up to the point in which one dollar spent in precaution reduces expected harm and the uncertainty burden by one dollar. The loss would be distributed in proportion to the tolerance to uncertainty of each individual (Appendix A5). Standard liability rules cannot mimic this outcome and are therefore bound to be (first best) inefficient.

Under Strict Liability, courts should set damages so as to simultaneously provide incentives to take care and reduce the uncertainty burden for the parties. If greater care induces both a reduction in the mean probability of harm and in the ambiguity perceived by the victim, then optimal damages increase with the degrees of risk and ambiguity aversion of the victim. If the victim is very sensitive to uncertainty, damages should get close to the full extent of the harm suffered. They will however fall short of full compensation, as some uncertainty sharing is always optimal.

Under Negligence, the optimal standard should balance benefits and costs of prevention. The benefits are calculated on the basis of the effect of prevention on safety and uncertainty. A measure that improves safety (in expected terms) might increase uncertainty: if that is the case, then mean safety should be traded off, at the margin, against the predictability/accuracy of prevention. ${ }^{25}$

Since both Strict Liability and Negligence can effectively provide incentives to take care, the comparison between the two hinges on their ability to suitably allocate the uncertainty burden between the parties. Depending on their ability to tolerate risk and

\footnotetext{
${ }^{25}$ In the special case in which negligence centers around whether the use of a potentially toxic substance should be allowed or prohibited, uncertainty aversion marginally shifts the balance in favour of prohibition, in line with Comment c, "Toxic substances and disease" Restatement (Third) of Torts, § 28 (which suggests that scientific uncertainty might call for a cautionary approach in the determination of the toxicity of chemical agents).
} 
ambiguity, one of the parties can have a comparative advantage in this respect. My model provides for a clear-cut identification of the best uncertainty bearer: the party that has the smallest uncertainty index is the best bearer (this index can be modified to include optimism/pessimism attitudes, as discussed in Appendix A6).

An important point made in this paper is that Strict Liability and Negligence are symmetric in their ability to allocate uncertainty only if damages (under Strict Liability) are fully compensatory. If they are not, i.e. if courts can under-compensate the victim, then Strict Liability is marginally superior to Negligence: if the injurer and the victim are equally good uncertainty bearers, then Strict Liability dominates (as it can shift some of the burden on the injurer). Negligence dominates only if the victim is substantially more averse to uncertainty than the injurer or if harm is distributed on many victims.

The policy implications of my results are quite clear. Uncertainty aversion affects both the determination of the optimal standard and the optimal allocation of the loss. As such, it provides an additional criterion for the choice between liability rules.

The assessment of the impact of uncertainty of harm on the welfare of the parties, however, is not an easy task. Estimates about the degree of risk aversion of typical households have been obtained from insurance data (see footnote 15). The size of the epistemic uncertainty associated with different hazards has been the object of through investigations. Extensive research by social psychologists shows that "knowability" is a fundamental dimension of risk perception (see, for instance, Slovic (2000)). Individual responses to epistemic uncertainty, however, can vary.

For harms related to product's defects and environmental hazards, one might argue that the cost of uncertainty is likely to be larger if it falls on the victims rather than on big firms and manufacturers, which might rely on more precise estimates of the probability of harm and might have better chances to get insurance (and thus improve their tolerance to uncertainty). So, strict liability for products-related harms and for environmental harms might be preferable - in line with the current legal system. This insight, however, has to be balanced against the observation that, for dispersed harms, negligence allows for better uncertainty spreading. 
Note how my arguments in favor or against the Negligence rule differ from those of Teitelbaum (2007). In my view, risk and ambiguity are the basic dimensions of uncertainty: both contribute to the social cost of accidents. For Teitelbaum, ambiguity is close to a perception error that needs to be corrected by the legal system (by means of technical standards). The ambiguity of my model, instead, results from the difficulty - sometimes impossibility - of calculating objective probabilities. The cost of this uncertainty cannot be eliminated: the party that bears the loss inevitably also bears the cost of uncertainty.

The mean-variance model developed in this paper abstracts away from income effects, which is a special blessing for welfare analysis. One purpose of this paper is to illustrate how traditional cost-benefit analysis can be enriched to take account of such important factors like risk aversion and ambiguity aversion. The tools for this extension are relatively handy and can be applied to many other legal settings, including litigation and contract law. 


\section{Appendix}

A1. Mean-Variance approximation. Given the investment in care $x$, let $\mu$ be the probability distribution describing the agent's beliefs about the probability of harm $\pi(x)$. These probabilities can belong to an interval or a discrete set. For any probability $\pi(x)$, the expected utility of the agent is: $E U_{\pi(x)}=(1-\pi(x)) u(i)+\pi(x) u(i-\ell)$, where $i$ is her net income and $\ell$ the loss. The welfare functional is

$$
W=E_{\mu}\left(\varphi\left(E U_{\pi(x)}\right)\right)
$$

where $E_{\mu}$ is the expectation over the prior distribution of $\pi(x)$, and $\varphi$ a function capturing the agent's attitude towards ambiguity.

If $\varphi$ is linear, the maximization of $W$ is equivalent to the maximization of

$$
\bar{W}=E_{\mu}\left(E U_{\pi(x)}\right)=\left(1-E_{\mu}(\pi(x))\right) u(i)+E_{\mu}(\pi(x)) u(i-\ell)=E U_{p(x)},
$$

where $p(x)=E_{\mu}(\pi(x))$ is the mean of the possible probabilities of harm (those belonging to the prior set). In this case, the agent behaves like an Expected Utility maximizer: she only cares about the reduced probability $p(x)$ of the compound lottery, and is said to be "ambiguity neutral."

If $\varphi$ is concave, the agent is averse to mean preserving spreads of the beliefs:

$$
E_{\mu}\left(\varphi\left(E U_{\pi(x)}\right)\right)<\varphi\left(E_{\mu}\left(E U_{\pi(x)}\right)\right)
$$

For any probability $\pi(x)$, the certainty equivalent of the harm lottery (such that $u\left(c_{\pi(x)}\right)=$ $\left.E U_{\pi(x)}\right)$ can be written as:

$$
c_{\pi(x)}=i-\pi(x) \ell-\frac{1}{2} \rho \sigma_{\pi(x)}^{2} \ell^{2}+o\left(\ell^{2}\right)
$$

where $\pi(x) \ell$ is the expected loss, $\sigma_{\pi(x)}^{2}=\pi(x)(1-\pi(x))$ the variance of the unit loss, $\rho$ the Arrow-Pratt degree of absolute risk aversion of the utility function, and $o\left(\ell^{2}\right)$ an expression that includes terms of third and higher order. If the loss is small or if $u^{\prime \prime \prime}$ is close to zero, the last term can be neglected. 
If we let

$$
w_{\pi(x)}=\pi(x)+\frac{1}{2} \rho \sigma_{\pi(x)}^{2} \ell
$$

the certainty equivalent becomes: $c_{\pi(x)} \simeq i-\ell w_{\pi(x)}$, where $w_{\pi(x)}$ is a random variable that depends on $\pi(x)$. Let $v(i)=\varphi(u(i))$. Thus, we can write the welfare functional as ${ }^{26}$

$$
W=E_{\mu}\left(v\left(c_{\pi(x)}\right)\right)
$$

By using a second order expansion, we get an approximation for the total certainty equivalent $C(x)$, with $v(C(x))=E_{\mu}\left(v\left(c_{\pi(x)}\right)\right)$, which takes into account the uncertainty over $w_{\pi(x)}$ :

$$
C(x)=i-\ell E_{\mu}\left(w_{\pi(x)}\right)-\frac{1}{2} \lambda_{v} \ell^{2} \sigma_{\mu}^{2}\left(w_{\pi(x)}\right)+o\left(\ell^{2}\right),
$$

where $\lambda_{v}=-\frac{v^{\prime \prime}\left(i-\ell E_{\mu}\left(w_{\pi(x)}\right)\right)}{v^{\prime}\left(i-\ell E_{\mu}\left(w_{\pi(x)}\right)\right)}$ is the Arrow-Pratt index of absolute risk aversion of the $v$ function. From eq. (19), we get

$$
E_{\mu}\left(w_{\pi(x)}\right)=p(x)+\frac{1}{2} \rho \ell E_{\mu}\left(\sigma_{\pi(x)}^{2}\right)
$$

where $p(x)=E_{\mu}(\pi(x))$ is the mean probability of harm, and

$$
\sigma_{\mu}^{2}\left(w_{\pi(x)}\right)=\sigma_{\mu}^{2}(\pi(x))+\sigma_{\mu}^{2}\left(\frac{1}{2} \rho \sigma_{\pi(x)}^{2} \ell\right)+2 \operatorname{Cov}\left(\pi(x), \frac{1}{2} \rho \sigma_{\pi(x)}^{2} \ell\right) .
$$

Thus (omitting the argument of $\pi(x)$ ),

$$
\begin{aligned}
& C(x)= \\
& i-\ell\left[p(x)+\frac{1}{2} \rho \ell E_{\mu}\left(\sigma_{\pi}^{2}\right)\right]-\frac{1}{2} \lambda_{v} \ell^{2}\left[\sigma_{\mu}^{2}(\pi)+\left(\frac{1}{2} \rho \ell\right)^{2} \sigma_{\mu}^{2}\left(\sigma_{\pi}^{2}\right)+\rho \ell \operatorname{Cov}\left(\pi, \sigma_{\pi}^{2}\right)\right]+o\left(\ell^{2}\right)= \\
& i-p(x) \ell-\frac{1}{2} \rho \ell^{2} E_{\mu}\left(\sigma_{\pi}^{2}\right)-\frac{1}{2} \lambda_{v} \ell^{2} \sigma_{\mu}^{2}(\pi)-\ell^{4}\left(\frac{1}{2} \rho\right)^{2} \sigma_{\mu}^{2}\left(\sigma_{\pi}^{2}\right)-\frac{1}{2} \lambda_{v} \rho \ell^{3} \operatorname{Cov}\left(\pi, \sigma_{\pi}^{2}\right)+o\left(\ell^{2}\right)= \\
& i-p(x) \ell-\frac{1}{2} \rho \ell^{2} E_{\mu}\left(\sigma_{\pi}^{2}\right)-\frac{1}{2} \lambda_{v} \ell^{2} \sigma_{\mu}^{2}(\pi)+o\left(\ell^{2}\right) .
\end{aligned}
$$

The total uncertainty equivalent is thus approximately equal to: i) income less the expected loss, ii) less the mean of the Arrow-Pratt risk premium, iii) less a term which depends on the

\footnotetext{
${ }^{26}$ I am grateful to Fabio Maccheroni and Massimo Marinacci for providing the steps needed to reconcile my approximation to their general result (presented in Maccheroni et al. (2013), Appendix A1). My approximation applies to unilateral risks, theirs to symmetric risks. Related approximations are obtained by Jewitt and Mukerji (2011) and Izhakian and Benninga (2011)
} 
variance of the belief.

Since $v(i)=\varphi(u(i))$ and $\frac{v^{\prime \prime}}{v^{\prime}}=\frac{\varphi^{\prime \prime}}{\varphi^{\prime}}+\frac{u^{\prime \prime}}{u^{\prime}}$, we get $\lambda_{v}=\theta+\rho$, with $\theta=-\frac{\varphi^{\prime \prime}}{\varphi^{\prime}}$. Hence, omitting third and higher order terms:

$$
\begin{aligned}
C(x) & \simeq i-p(x) \ell-\frac{1}{2} \rho \ell^{2} E_{\mu}\left(\sigma_{\pi(x)}^{2}\right)-\frac{1}{2}[\theta+\rho] \ell^{2} \sigma_{\mu}^{2}(\pi(x)) \\
& \simeq i-p(x) \ell-\frac{1}{2} \rho \ell^{2}\left[E_{\mu}\left(\sigma_{\pi(x)}^{2}\right)+\sigma_{\mu}^{2}(\pi(x))\right]-\frac{1}{2} \theta \ell^{2} \sigma_{\mu}^{2}(\pi(x))
\end{aligned}
$$

Note that

$$
\begin{aligned}
E_{\mu}\left(\sigma_{\pi(x)}^{2}\right) & =E_{\mu}(\pi(x)(1-\pi(x))) \\
& =p(x)-E_{\mu}\left(\pi(x)^{2}\right)=p(x)-\left[\sigma_{\mu}^{2}(\pi(x))+p(x)^{2}\right] \\
& =p(x)(1-p(x))-\sigma_{\mu}^{2}(\pi(x))=\sigma_{p(x)}^{2}-\sigma_{\mu}^{2}(\pi(x))
\end{aligned}
$$

Thus,

$$
C(x) \simeq i-p(x) \ell-\frac{1}{2} \rho \sigma_{p(x)}^{2} \ell^{2}-\frac{1}{2} \theta \sigma_{\mu}^{2}(\pi(x)) \ell^{2} .
$$

Under ambiguity aversion, the certainty equivalent is equal to income less expected loss less the risk premium attendant with the mean probability $p(x)$, less an ambiguity premium which depends on the variance of the beliefs $\sigma_{\mu}^{2}(\pi(x))$. The uncertainty premium $U P(x)=$ $E_{\mu}(\pi(x) \ell)-C(x)$ is therefore:

$$
U P(x)=\frac{1}{2} \rho \sigma_{p(x)}^{2} \ell^{2}+\frac{1}{2} \theta \sigma_{\mu}^{2}(\pi(x)) \ell^{2} \equiv \frac{1}{2} \Psi(x) \ell^{2}
$$

The uncertainty premium is equal to the sum of the risk and ambiguity premia.

A2. Comparative statics under Negligence. From eq. (13), we get

$$
f(\bar{x})=1+p^{\prime}(\bar{x})\left(H+(1-2 p(\bar{x})) \frac{1}{2} H^{2} \rho_{V}\right)+\frac{1}{2} \theta_{V} H^{2} \frac{\partial \sigma_{\mu_{V}}^{2}(\bar{x})}{\partial x}=0 .
$$

We have 


$$
\begin{aligned}
& \operatorname{sign}\left(\frac{\partial \bar{x}}{\partial \rho_{V}}\right)=\operatorname{sign}\left(-\frac{\partial^{2} L(\bar{x})}{\partial \bar{x} \partial \rho_{V}} / \frac{\partial^{2} L(\bar{x})}{\partial \bar{x}^{2}}\right)=\operatorname{sign}\left(-p^{\prime}(\bar{x})(1-2 p(\bar{x})) \frac{1}{2} H^{2} \rho_{V}\right), \\
& \operatorname{sign}\left(\frac{\partial \bar{x}}{\partial \theta_{V}}\right)=\operatorname{sign}\left(-\frac{\partial^{2} L(\bar{x})}{\partial \bar{x} \partial \theta_{V}} / \frac{\partial^{2} L(\bar{x})}{\partial \bar{x}^{2}}\right)=\operatorname{sign}\left(\frac{\partial \sigma_{\mu_{V}}^{2}(\bar{x})}{\partial x}\right)
\end{aligned}
$$

Thus, $\frac{\partial \bar{x}}{\partial \rho_{V}}>0$ thanks to Assumption 2, and $\frac{\partial \bar{x}}{\partial \theta_{V}}<0$ if, and only if, $\frac{\partial \sigma_{\mu_{V}}^{2}(\bar{x})}{\partial x}<0$.

A3. Strict Liability vs. Negligence. We have $L^{N}\left(x^{s}\right)<L^{S}\left(x^{s}\right)$ if, and only if (omitting arguments):

$$
\frac{d^{*}}{h}>\frac{2 \Psi_{V}}{\Psi_{I}+\Psi_{V}}
$$

If the victim is risk and ambiguity neutral $\left(\rho_{V} \rightarrow 0, \theta_{V} \rightarrow 0\right)$, we have, from eq. (11)

$$
L^{S \prime}=\frac{\partial x^{\circ}}{\partial d} p^{\prime}(h-d)+d\left[p(1-p) \rho_{I}+\theta_{I} \sigma_{\mu_{I}}^{2}\right]
$$

For $d \rightarrow 0$, we get

$$
L^{S \prime}(0)=\frac{\partial x^{\circ}}{\partial d} p_{x}^{\prime} h<0:
$$

optimal damages $d^{*}$ do not drop to zero when the victim is uncertainty neutral. Thus, $\frac{d^{*}}{h}$ is surely greater than $\frac{2 \Psi_{V}}{\Psi_{I}+\Psi_{V}}$ if $\Psi_{V}$ sufficiently small. This proves Proposition 4.

A4. Bilateral accidents. Negligence. Let $\bar{x}$ be the due level of care for the injurer and $y$ the level of care taken by the victim. If the injurer meets the standard of care (as I assume), the victim will chose the level of care that maximizes his certainty equivalent

$$
C_{V}=i_{V}-y-p(\bar{x},) h-\frac{1}{2} p(\bar{x}, y)[1-p(\bar{x}, y)] h^{2} \rho_{V}-\frac{1}{2} \theta_{V} \sigma_{\mu_{V}}^{2}(\pi(\bar{x}, y)) h^{2}
$$

Thus, he will chose $y=\widehat{y}$ so that

$$
1+p_{y}^{\prime}(\bar{x}, \widehat{y})\left(h+\frac{1}{2}(1-2 p(\bar{x}, \widehat{y})) h^{2} \rho_{V}\right)+\frac{1}{2} \theta_{V} \frac{\partial \sigma_{\mu_{V}}^{2}(\pi(\bar{x}, \widehat{y}))}{\partial y} h^{2}=0
$$

Social loss is:

$$
L^{N}(\bar{x})=\bar{x}+\hat{y}+p(\bar{x}, \widehat{y}) h+\frac{1}{2} \Psi_{V}(\bar{x}, \widehat{y}) h^{2},
$$


with

$$
\begin{gathered}
L^{\prime N}(\bar{x})=1+p_{x}^{\prime}(\bar{x}, \widehat{y})\left(h+\frac{1}{2}(1-2 p(\bar{x}, \widehat{y})) h^{2} \rho_{V}\right)+\frac{1}{2} \theta_{V} \frac{\partial \sigma_{\mu_{V}}^{2}\left(\pi_{j}(\bar{x}, \widehat{y})\right)}{\partial x} h^{2}+ \\
\frac{\partial \hat{y}_{j}}{\partial \bar{x}}\left[1+p_{y}^{\prime}(\bar{x}, \widehat{y})\left(h+\frac{1}{2}(1-2 p(\bar{x}, \widehat{y})) h^{2} \rho_{V}\right)+\frac{1}{2} \theta_{V} \frac{\partial \sigma_{\mu_{V}}^{2}(\pi(\bar{x}, \widehat{y}))}{\partial y} h^{2}\right] .
\end{gathered}
$$

The term within square brackets is nil in view of (23).

Thus, the optimal standard of care should solve:

$$
1+p_{x}^{\prime}(\bar{x}, \widehat{y})\left(h+\frac{1}{2}(1-2 p(\bar{x}, \widehat{y})) h^{2} \rho_{V}\right)+\frac{1}{2} \theta_{V} \frac{\partial \sigma_{\mu_{V}}^{2}(\pi(\bar{x}, \widehat{y}))}{\partial x} h^{2}=0 .
$$

Eq. (23), together with (25), determine the equilibrium levels of care $x^{N}, y^{N}$, (where $N$ stands for Negligence). By implicit differentiation, we get (omitting arguments)

$$
\operatorname{sign}\left[\frac{\partial x^{N}}{\partial \theta_{V}}\right]=\operatorname{sign}\left[\frac{\partial^{2} L^{N}}{\partial y^{2}} \frac{\partial^{2} L^{N}}{\partial x \partial \theta_{V}}-\frac{\partial^{2} L^{N}}{\partial x \partial y} \frac{\partial^{2} L^{N}}{\partial y \partial \theta_{V}}\right],
$$

with $\frac{\partial^{2} L}{\partial y^{2}} \geq 0$ (since this is a minimum) and

$$
\begin{aligned}
\frac{\partial^{2} L^{N}}{\partial x \partial y} & =\frac{\partial^{2} p(x, \hat{y})}{\partial x \partial y}\left[h+\frac{1}{2}(1-2 p(x, \hat{y})) h^{2} \rho_{V}\right]-\frac{\partial p}{\partial x} \frac{\partial p}{\partial y} h^{2} \rho_{V}+\frac{1}{2} \theta_{V} h^{2} \frac{\partial^{2} \sigma_{\mu_{V}}^{2}(\pi(\bar{x}, \hat{y}))}{\partial x \partial y} \\
\frac{\partial^{2} L^{N}}{\partial x \partial \theta_{V}} & =\frac{1}{2} h^{2} \frac{\partial \sigma_{\mu_{V}}^{2}(\pi(\bar{x}, \hat{y}))}{\partial x}, \quad \text { and } \quad \frac{\partial^{2} L^{N}}{\partial y \partial \theta_{V}}=\frac{1}{2} h^{2} \frac{\partial \sigma_{\mu_{V}}^{2}(\pi(\bar{x}, \hat{y}))}{\partial y}
\end{aligned}
$$

Let us assume that $\frac{\partial^{2} p(\bar{x}, \hat{y})}{\partial x \partial y} \leq 0$ and $\frac{\partial^{2} \sigma_{\mu_{V}}^{2}(\pi(\bar{x}, \hat{y}))}{\partial x \partial y} \leq 0: x$ and $y$ are not substitutes with respect to harm probability and ambiguity.

If $\frac{\partial \sigma_{\mu_{V}}^{2}(\pi(\bar{x}, \hat{y}))}{\partial x}<0$ and $\frac{\partial \sigma_{\mu_{V}}^{2}(\pi(\bar{x}, \hat{y}))}{\partial y}<0$, then: $\frac{\partial x^{N}}{\partial \theta_{V}}>0, \frac{\partial y^{N}}{\partial \theta_{V}}>0$. In plain words, when the levels of care $x$ and $y$ reduce the ambiguity perceived by the victims, an increase in the victims' degree of ambiguity aversion calls for an increase in the due level of care, on the assumption that cross-effects do not go in the opposite direction (or that they are small enough). Conversely, if $\frac{\partial \sigma_{\mu_{V}}^{2}(\pi(\bar{x}, \hat{y}))}{\partial x}>0$ and $\frac{\partial \sigma_{\mu_{V}}^{2}(\pi(\bar{x}, \hat{y}))}{\partial y}>0$, then: $\frac{\partial x^{N}}{\partial \theta_{V}}<0, \frac{\partial y^{N}}{\partial \theta_{V}}<0$.

We also have: $\frac{\partial x^{N}}{\partial \rho_{V}}>0$, and $\frac{\partial y^{N}}{\partial \rho_{V}}>0$.

Strict liability with the defence of contributory negligence. Let us assume that damages are such that it is in the interest of the victims to meet the due standard of care (in other words, damages are not too low). The victim will exert care $\bar{y}$. In turn, the injurer sets $x^{\circ}$ so that

$$
1+p_{x}^{\prime}\left(x^{\circ}, \bar{y}\right) d+\frac{1}{2} \frac{\partial^{2} \Psi_{I}\left(x^{\circ}, \bar{y}\right)}{\partial x} d^{2}=0
$$


If $\frac{\partial \sigma_{\mu_{I}}^{2}\left(\pi\left(x^{\circ}, \bar{y}\right)\right)}{\partial x}<0$, then: $\frac{\partial^{2} \Psi_{I}\left(\pi\left(x^{\circ}, \bar{y}\right)\right)}{\partial x}<0$ and $\frac{\partial x^{\circ}}{\partial d}>0$.

Optimal damages are obtained from the minimization of (omitting arguments):

$$
\begin{aligned}
L^{S L}(d)=x^{\circ}+\bar{y}+p & \left(x^{\circ}, \bar{y}\right) h+\frac{1}{2} \Psi_{I}\left(x^{\circ}, \bar{y}\right) d^{2} \\
& +\frac{1}{2} \Psi_{V}\left(x^{\circ}, \bar{y}\right)(h-d)^{2} .
\end{aligned}
$$

Thus, courts will set $d$ and $\bar{y}$ so that, using (26):

$$
\begin{aligned}
\frac{\partial L^{S L}(d)}{\partial \bar{y}}=1+p_{\bar{y}}^{\prime}\left(x^{\circ}, \bar{y}\right) h+\frac{1}{2} \frac{\partial \Psi_{I}\left(x^{\circ}, \bar{y}\right)}{\partial \bar{y}} d^{2}+\frac{1}{2} \frac{\partial \Psi_{V}\left(x^{\circ}, \bar{y}\right)}{\partial \bar{y}}(h-d)^{2} & \\
+ & \frac{\partial x^{\circ}}{\partial \bar{y}}\left[p_{x}^{\prime}\left(x^{\circ}, \bar{y}\right)(h-d)+\frac{1}{2} \frac{\partial \Psi_{V}\left(x^{\circ}, \bar{y}\right)}{\partial x^{\circ}}(h-d)^{2}\right]=0 \\
\frac{\partial L^{S L}(d)}{\partial d}=\Psi_{I}( & \left.x^{\circ}, \bar{y}\right) d-\Psi_{V}\left(x^{\circ}, \bar{y}\right)(h-d) \\
+\frac{\partial x^{\circ}}{\partial d}\left[p_{x}^{\prime}\left(x^{\circ}, \bar{y}\right)(h-d)+\frac{1}{2} \frac{\partial \Psi_{V}\left(x^{\circ}, \bar{y}\right)}{\partial x^{\circ}}(h-d)^{2}\right] & =0 .
\end{aligned}
$$

For $d=h$, marginal loss simplifies to

$$
\frac{\partial L^{S L}(d)}{\partial d}=[1+(n-1) \varrho] \Psi_{I}\left(x^{\circ}, \bar{y}\right) d \geq 0 .
$$

Thus, as in the unilateral case, at the optimum: $d^{*}<h$ if the injurer is not uncertainty neutral.

Dominance. Let us compare Negligence and Strict Liability with fully compensatory damages $(h=d)$. Given care levels $x$ and $y$, constrained Strict Liability is preferable if, and only if (from 24 and 27):

$$
\widehat{L}^{S L}(x, y)<L^{N}(x, y) \Leftrightarrow \Psi_{I}(x, y)<\Psi_{V}(x, y)
$$

as in the unilateral case (see ineq. 15).

If Condition $I$ holds, then,

$$
\widehat{L}^{S L}\left(x^{N}, y^{N}\right)<L^{N}\left(x^{N}, y^{N}\right)
$$

where $x^{N}$ and $y^{N}$ are the levels of care taken by the parties under negligence. Social loss is even smaller, under $\widehat{L}^{S L}$, if the injurer takes the optimal level of care $x^{\circ}$, given the level of care $\bar{y}$ optimally set by the courts (under Strict Liability with contributory negligence). In fact, $\left(x^{\circ}, \bar{y}\right)$ minimizes Social Loss: if the courts could also select $x$, they would just pick $x^{\circ}$ 
(this can be seen from the first order conditions). Thus,

$$
\widehat{L}^{S L}\left(x^{\circ}, \bar{y}\right) \leq \widehat{L}^{S L}\left(x^{N}, y^{N}\right)
$$

If courts can optimally chose $d$, social loss further decreases. Thus, Strict Liability dominates negligence.

Similarly, if Condition V holds, then,

$$
L^{N}\left(x^{s}, y^{s}\right)<L^{S L}\left(x^{s}, y^{s}\right)
$$

where $x^{s}$, and $y^{s}$ are the levels of care under Strict Liability. Social loss further decreases if courts select the socially optimal standard $x^{N}$, while the victim selects his welfare maximizing level of care $y^{N}$. Again, $\left(x^{N}, y^{N}\right)$ minimize social loss, even if $x$ and $y$ are chosen by different subjects (see eqs. (23) and (25)). Thus, also under bilateral accidents, Propositions 3 and 4 apply.

A5. Efficient loss sharing. Let us consider the allocation that parties themselves would agree on if they could write an ex-ante contract specifying the level of precaution to be taken by the injurer and the way in which the loss is shared. This contract would also specify an up-front transfer between them. ${ }^{27}$ Let us consider the case with $n$ identical victims.

Full efficiency is obtained from the maximization of Social Welfare

$$
S W=C_{I}+n C_{V}=i_{I}-x-p(x) n d-\frac{1}{2} \Psi_{I}(x)(n d)^{2}+n\left[i_{V}-p(x)(h-d)-\frac{1}{2} \Psi_{I}(x) d^{2}\right],
$$

Since $i_{I}, i_{V}$, and $h$ are constants, the problem is equivalent to the minimization of Social Loss:

$$
\min L=x+p(x) n h+\frac{1}{2} \Psi_{I}(x)(n d)^{2}+n \frac{1}{2} \Psi_{V}(x)(h-d)^{2} .
$$

Social loss includes the expenditure in prevention, expected harm, and the uncertainty premia associated with the risk of harm.

${ }^{27}$ The same transfer could be used by the policy-maker to address distributional concerns, which are, therefore, out of the picture. See Miceli and Segerson (1995). 
From the minimization of $L$, we get (omitting arguments): ${ }^{28}$

$$
\begin{aligned}
& \frac{\partial L}{\partial x}=1+p^{\prime}(x) n h+\frac{1}{2} \Psi_{I}^{\prime}(x)(n d)^{2}+n \frac{1}{2} \Psi_{I}^{\prime}(x) d^{2}=0 \\
& \frac{\partial L}{\partial d}=n \Psi_{I}(x) n d-n \Psi_{V}(x)(h-d)=0
\end{aligned}
$$

The first equation determines the efficient level of care $x^{e}$ : one dollar spent in precaution should reduce expected harm and the uncertainty burden of injurer and victims by one dollar. The second equation pertains to the optimal allocation of the loss: this should be shared by the parties according to their disposition towards uncertainty. Given the level of care, (fully) efficient damages are therefore, from (31)

$$
d^{e}=\frac{\Psi_{V}\left(x^{e}\right)}{\Psi_{V}\left(x^{e}\right)+n \Psi_{I}\left(x^{e}\right)} h
$$

The share of the loss borne by each party decreases with the degree of uncertainty aversion of that party and increases with the degree of uncertainty aversion of the other party. ${ }^{29}$ If injurer and victims were equally averse to uncertainty, $\Psi_{V}\left(x^{e}\right)=\Psi_{I}\left(x^{e}\right)$, then they would split the loss in equal parts: $d^{e}=\frac{1}{n+1} h$. The injurer bears $n d^{e}=\frac{n}{n+1} h$, while each victim bears: $h-d^{e}=\frac{n}{n+1} h$.

If $n \rightarrow \infty$, then $x^{e}$ goes to infinity while $d^{e}$ goes to nil. If $x$ is bounded above $\left(x \leq x^{\max }\right)$, then Negligence with $\bar{x}=x^{\max }$ is approximately first best efficient, as shown by Nell and Richter (2003) for CARA utility functions.

A6. Diverging expectations - neo-additive capacity. A substantial departure from EU theory obtains if parties are assumed not to agree on the expected probability of harm: $p_{I}(x) \neq$ $p_{V}(x)$. This cases arises, for instance, when parties attach different weights to alternative explanatory models of harm or, more generally, when they subscribe to different causation

\footnotetext{
${ }^{28}$ Here and in the rest of the paper, I assume that the mean probability of harm function, $p(x)$, is convex enough to guarantee quasi-convexity of the social loss functions.

${ }^{29}$ This linear sharing rule was first obtained, for the case of simple risk aversion, by Greenwood and Ingene (1980), p. 1061. More generally, this result implies that the loss should be distributed on all individuals in society (not just injurer and victims), in proportion to their ability to tolerate uncertainty. If the loss can be spread on an infinite number of individuals, we turn to the characterization of the first best provided by Shavell (1982), which prescribes $1+p^{\prime}(x) n h=0$ and full insurance for all risk averse parties.
} 
narratives. A special case is that in which each party formulates a simple belief: the injurer believes that the probability of harm is $\pi_{I}(x)$, the victim that it is $\pi_{V}(x) .{ }^{30}$ This case tends to provide a straightforward policy implication: if one of the parties is (sufficiently) more optimistic than the other, then it should bear the loss. So, if $\pi_{I}(x)<\pi_{V}(x)$ for all $x$, Strict Liability is preferable (both the expected loss and the risk premium borne by the injurer are smaller than that borne by the victim under Negligence). Here, liability law allows parties to insure each other against their own pessimistic attitudes. It is not clear, however, whether courts would support such a solution or whether they would instead impose their own view (a third belief) on the parties. ${ }^{31}$

If we let $p_{I}(x) \neq p_{V}(x)$ in the smooth ambiguity model, a pessimism/optimism bias is introduced. The choice between liability rules depends now on size of the uncertainty premia $\left(\Psi_{V}(x)-\Psi_{I}(x)\right)$ and on optimism/pessimism $\left(p_{V}(x)-p_{I}(x)\right)$. Again, it is not clear whether here courts should rely on the beliefs of the parties or on the beliefs of a "reasonable person." 32 If the difference between $p_{V}(x)$ and $p_{I}(x)$ is large, foreseeability of harm might fail. For example, the victim might believe that a conduct is highly dangerous while the injurer and the court do not: the victim cannot recover because harm is not foreseeable.

An alternative view is to assume that parties share the same belief $q(x)$ about the probability of harm, but they interpret this probability in different ways. This approach characterizes the "first generation" models of ambiguity aversion, pioneered by Schmeidler (1989), and successfully applied to liability law by Teitelbaum (2007). Specifically, Teitelbaum formalizes ambiguity along the lines of the neo-additive model of Chateauneuf et al. (2007), in which

\footnotetext{
${ }^{30}$ The diverging beliefs case has been successfully employed in the litigation literature to explain settlement failure. See Priest and Klein (1984).

${ }^{31}$ In fact, one might argue that, here, the concept of Pareto efficiency itself becomes problematic. Gilboa et al. (2014) and Gayer et al. (2014) develop the concept of "no-betting Pareto efficiency" (there does not exist a different allocation that makes everybody better off according to their own beliefs and according to a belief $\pi$, when shared by all parties). A liability rule that allocates the loss to the party that is more pessimist - although not Pareto efficient - might be no-betting Pareto efficient: parties might prefer that allocation if they were to set their different beliefs aside and decide/pretend to share the same belief.

${ }^{32}$ In the words of Judge Cardozo: "The risk reasonably to be perceived defines the duty to be obeyed" (Palsgraf v. Long Island, 248 N.Y. 339 (1928)). Objective probabilities, of course, are not an option, because, if they had existed, they would have been used by the parties themselves.
} 
parties distinguish only three types of events: impossible, possible, and certain. In this model, ambiguity is defined as a lack of confidence in the probability of harm. The more severe this lack of confidence, the further away agents move from Expected Utility by attaching greater weight to extreme payoffs (minimum and maximum utility). Thus, agents tend to display either pessimism or optimism, similarly to the diverging expectations model.

Since the neo-additive model is formally equivalent to the well known RDEU model (and Cumulative Prospect Theory, under symmetric treatment of gains and losses), in what follows I highlight two interesting implications of this approach (see Franzoni (2014) for an extensive analysis).

First, let us consider optimal standard setting under Negligence. If victims have little confidence in the probability of harm, they will not fully savor the benefits of greater care. In the extreme case of complete lack of confidence, victims will regard all "possible" outcomes in the same way ( $50 \%$ likely), independently of the level of care taken by the injurer. The consequence of "likelihood insensitivity" is that the efficient standard will be very low (marginal costs are savored, marginal benefits are not). ${ }^{33}$

Second. Let us consider optimal uncertainty sharing under Strict Liability. When parties are pessimist (they attach large weight to minimum utility), very small risks (small losses) can have a substantial impacts on their welfare. Given compensatory damages, a small reduction of $d$ has a first order effect on the welfare level of the victim, so it might be undesirable (while it has a second order effect under standard risk aversion and smooth ambiguity aversion). In particular, if the victim is substantially more pessimist than the injurer, fully compensatory damages are optimal $\left(d^{*}=h\right)$. Neo-additive ambiguity aversion elevates uncertainty to a first order effect - as originally suggested by Segal and Spivak (1990).

\section{References}

Abdellaoui, M., A. Baillon, L. Placido, and P. P. Wakker (2011). The rich domain of uncertainty: Source functions and their experimental implementation. The American Economic Review 101(2), 695-723.

\footnotetext{
${ }^{33}$ See Abdellaoui et al. (2011) for recent estimates of likelihood insensitivity.
} 
Alary, D., C. Gollier, and N. Treich (2013). The Effect of Ambiguity Aversion on Insurance and Self-protection. The Economic Journal 123(573), 1188-1202.

Attanasi, G., C. Gollier, A. Montesano, and N. Pace (2014). Eliciting ambiguity aversion in unknown and in compound lotteries: a smooth ambiguity model experimental study. Theory and Decision 7r(4), 485-530.

Barseghyan, L., F. Molinari, T. O'Donoghue, and J. C. Teitelbaum (2013). The Nature of Risk Preferences: Evidence from Insurance Choices. American Economic Review 103(6), 2499-2529.

Ben-Shahar, O. (1998). Should Products Liability Be Based on Hindsight? Journal of Law, Economics, and Organization 41, 325-358.

Berger, L., H. Bleichrodt, and L. Eeckhoudt (2013). Treatment decisions under ambiguity. Journal of Health Economics 32(3), 559-569.

Chateauneuf, A., J. Eichberger, and S. Grant (2007). Choice under uncertainty with the best and worst in mind: Neo-additive capacities. Journal of Economic Theory 137(1), 538-567.

Cohen, A. and L. Einav (2007). Estimating Risk Preferences from Deductible Choice. American Economic Review 97(3), 745-788.

Conte, A. and J. D. Hey (2013). Assessing Multiple Prior Models of Behaviour under Ambiguity. Journal of Risk and Uncertainty 46(2), 113-132.

Ellsberg, D. (1961). Risk, Ambiguity and Savage Axioms. Quarterly Journal of Economics $75(4), 643-669$.

Etner, J., M. Jeleva, and J.-M. Tallon (2012). Decision Theory Under Ambiguity. Journal of Economic Surveys 26(2), 234-270.

Franzoni, L. A. (2014). Liability law and uncertainty spreading. Available at SSRN 2432861.

Gayer, G., I. Gilboa, L. Samuelson, and D. Schmeidler (2014). Pareto efficiency with different beliefs. The Journal of Legal Studies 43(S2), S151-S171.

Geistfeld, M. (2001). Scientific uncertainty and causation in tort law. Vand. L. Rev. 54, 1011. 
Gilboa, I. and M. Marinacci (2013). Ambiguity and the Bayesian paradigm. In D. Acemoglu, M. Arellano, and E. Dekel (Eds.), Advances in Economics and Econometrics, 10th World Congress. Cambridge University Press.

Gilboa, I., L. Samuelson, and D. Schmeidler (2014). No-betting-pareto dominance. Econometrica 82(4), 1405-1442.

Gilboa, I. and D. Schmeidler (1989). Maxmin expected utility with non-unique prior. Journal of mathematical economics 18(2), 141-153.

Graff Zivin, J. and A. Small (2003). Risk sharing in Coasean contracts. Journal of Environmental Economics and Management 45(2), 394-415.

Greenwood, P. and C. Ingene (1978). Uncertain externalities, liability rules, and resource allocation. The American Economic Review 68(3), 300-310.

Greenwood, P. and C. Ingene (1980). Uncertain Externalities, Liability Rules, and Resource Allocation: Reply. The American Economic Review 70(5), 1060-1063.

InstituteofMedicine (2014). Environmental Decisions in the Face of Uncertainty. Washington, D.C.: National Academies Press.

Izhakian, Y. and S. Benninga (2011). The Uncertainty Premium in an Ambiguous Economy. Quarterly Journal of Finance 01(02), 323-354.

Jewitt, I. and S. Mukerji (2011). Ordering Ambiguous Acts. Technical Report 553, Dept. of Economics, Oxford University.

Jolls, C. and C. R. Sunstein (2006). Debiasing through law. Journal of Legal Studies 35, 199-209.

Klibanoff, P., M. Marinacci, and S. Mukerji (2005). A smooth model of decision making under ambiguity. Econometrica 73(6), 1849-1892.

Langlais, E. (2010). Safety and the allocation of costs in large accidents. Available at SSRN 1688897. 
Maccheroni, F., M. Marinacci, and D. Ruffino (2013). Alpha as Ambiguity : Robust MeanVariance Portfolio Analysis. Econometrica 81(3), 1075-1113.

Miceli, T. J. and K. Segerson (1995). Defining efficient care: The role of income distribution. The Journal of Legal Studies 24(1), 189-208.

Millner, A., S. Dietz, and G. Heal (2013). Scientific ambiguity and climate policy. Environmental and Resource Economics 55(1), 21-46.

Mossin, J. (1968). Aspects of Rational Insurance Purchasing. Journal of Political Economy $76(4), 553-568$.

National-Research-Council (2009). Science and Decisions. Washington, D.C.: National Academies Press.

Nell, M. and A. Richter (2003). The design of liability rules for highly risky activitiesis strict liability superior when risk allocation matters? International Review of Law and Economics 23(1), 31-47.

Pratt, J. W. (1964). Risk aversion in the small and in the large. Econometrica 32(1-2), $122-136$.

Priest, G. L. and B. Klein (1984). The selection of disputes for litigation. The Journal of Legal Studies 13(1), 1-55.

Reyna, V. F., W. L. Nelson, P. K. Han, and M. P. Pignone (2015). Decision making and cancer. American Psychologist 70(2), 105.

Schaefer, H.-B. and F. Mueller-Langer (2009). Strict liability versus negligence. In M. Faure (Ed.), Tort Law and Economics, Number 1991, pp. 3-45. Cheltenham: Edward Elgar.

Schmeidler, D. (1989). Subjective probability and expected utility without additivity. Econometrica 57(3), 571-587.

Segal, U. and A. Spivak (1990). First order versus second order risk aversion. Journal of Economic Theory 51(1), 111-125.

Shavell, S. (1982). On liability and insurance. The Bell Journal of Economics 13(1), 120-132. 
Shavell, S. (2007). Liability for accidents. In A. M. Polinsky and S. Shavell (Eds.), Handbook of Law and Economics, Chapter 2. Oxford: Elsevier.

Slovic, P. E. (2000). The perception of risk. London: Earthscan Publications.

Snow, A. (2011). Ambiguity aversion and the propensities for self-insurance and selfprotection. Journal of Risk and Uncertainty 42(1), 27-43.

Sydnor, J. (2010). Over (Insuring) Modest Risks. American Economic Journal: Applied Economics 2(4), 177-199.

Teitelbaum, J. (2007). A unilateral accident model under ambiguity. Journal Legal Studies 36(2), 431-477.

Treich, N. (2010). The value of a statistical life under ambiguity aversion. Journal of Environmental Economics and Management 59(1), 15-26.

Wakker, P. P. (2010). Prospect Theory: For Risk and Ambiguity. Cambridge University Press. 


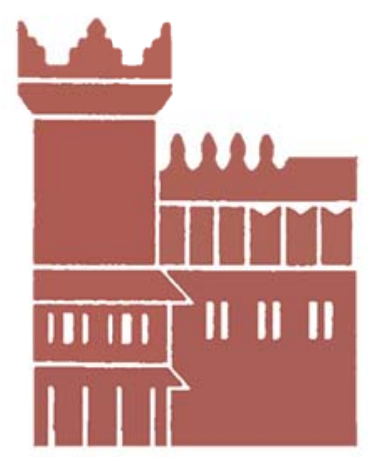

Alma Mater Studiorum - Università di Bologna DEPARTMENT OF ECONOMICS

Strada Maggiore 45

40125 Bologna - Italy

Tel. +39051 2092604

Fax +390512092664

http://www.dse.unibo.it 